\title{
Chapter 6 \\ Theory, Computers and the Parameterization of Demographic Behavior
}

\subsection{Introduction}

This is a story of two demographic models - their structure, rationale and interpretation, goodness of fit, and reception by demographers. The story raises interesting questions about demography - the structure of the discipline and its scientific community, attitudes toward theory and scientific methodology, and paths of future development. The two models are the Coale-McNeil (1972) and the Hernes (1972) models of first marriage. Developed at roughly the same time, the models have experienced rather different fates. The Coale-McNeil model has entered the standard repertoire of technical demography. It has been 'canonized,' as that term is used in a recent essay on culture by Griswold (1987) - that is, accepted by 'that elite group of specialists who may legitimately talk about value' (p. 11).

The Hernes model, by contrast, was largely ignored by mainstream demography until recently. It is not mentioned in the United Nations Manual X in the section on 'Nuptiality Models,' and is mentioned only briefly if at all in many other treatments of marriage in recent demographic literature.

Yet by ordinary scientific standards, the Hernes model does not seem inferior to Coale-McNeil. In some respects, it might even be judged a more elegant and wellrounded piece of scientific work. How can one explain its relative neglect? After a closer look at the two models, I return to this question below, suggesting that part of the answer lies in a predilection of mainstream demography for certain styles of work, with emphasis on measurement and the technical side of modelling, and a tendency to neglect issues of behavioral theory. More than is commonly realized, demography is two disciplines, one a branch of applied statistics dealing with population, the other a branch of social and behavioral science, focusing on

\footnotetext{
This chapter is a slightly revised version of a paper presented at the International Population Conference, Montreal, 1993. See International Union for the Scientific Study of Population, International Population Conference, Montreal, 1993, Vol. 3, pp. 377-388.
}

T.K. Burch, Model-Based Demography, Demographic Research Monographs,

DOI 10.1007/978-3-319-65433-1_6 
demographic behavior and aspiring to the development of behavioral substantive theory.

Viewed in terms of textbook social scientific methodology, mainstream demography's relative neglect of theory weakens its stature as a science. But recent methodological writings offer new and different views of the scientific enterprise, and suggest better prospects for abstract analytic theory in demography and other social sciences. A comparison of the two models of first marriage illustrates the issues as they pertain to contemporary demography.

\subsection{The Coale-McNeil Model}

The Coale-McNeil marriage model was first presented in two papers in the early 1970s (Coale 1971; Coale and McNeil 1972). The discussion here is based primarily on Coale's informal account of the model's development in a special issue of Population dedicated to Louis Henry (Coale 1977). ${ }^{1}$

The fundamental equation of first marriage risk for those eventually marrying in a cohort is given by:

$$
\begin{aligned}
\mathrm{g}(\mathrm{a})= & (0.1946 \Theta / \gamma) \exp \left[(-0.174 / \gamma)\left(\mathrm{a}-\mathrm{a}_{0}-6.06 \gamma\right)\right] \\
& -\exp \left[(-0.288 / \gamma)\left(\mathrm{a}-\mathrm{a}_{0}-6.06 \gamma\right)\right.
\end{aligned}
$$

Where $\theta$ is the proportion who will eventually marry, $a_{0}$ is the age at which marriage first begins, and $\gamma$ is '...the scale factor expressing the number of years of nuptiality in the given population which are equivalent to 1 year in the standard population' (U.N. 1983, pp. 22-23). The numerical constants in this expression were derived by fitting an earlier form to a standard schedule of first marriage based on 1865-1869 Swedish data.

Coale characterizes the process leading to the model partly as trial and error. It began with the realization that empirical curves of proportions ever-married could be made virtually identical by means of three transformations (Coale 1977, p. 132), adjusting for the earliest age at which the proportion visibly departs from zero (taken as a new origin), the proportions eventually marrying (determining a new vertical scale, from 0 to 1 ), and the steepness with which the curve rises over the period of most rapid increase (determining a new horizontal scale). This led to the conclusion that there was 'a common pattern of first marriage frequencies' (Coale 1977).

\footnotetext{
${ }^{1}$ Key elements of the model were developed by Griffith Feeney in the summer of 1971 (see Feeney 1972) and shared at a meeting that same summer. Coale and McNeil fully acknowledge Feeney's contribution.
} 
The next step was to find a functional form that could represent this common pattern. Experiments with various forms (initially a double exponential function) led to Eq. 6.1. Along the way, Coale began to look for a behavioral interpretation:

I expressed dissatisfaction with the double exponential risk function on the grounds that it did not provide any evident basis for an intuitive understanding of first marriages. In other words, it did not suggest a theory or model of nuptiality. One cannot infer what kind of individual behavior, or what form of social influence, causes the risk of first marriage (setting aside those who never marry) to follow a double exponential. (Coale 1977, p. 140) ${ }^{2}$

Griffith Feeney suggested an interpretation in terms of a normally distributed age of entry into the marriage market, and an exponentially distributed delay, or waiting time, between entry and marriage. Subsequent theoretical and mathematical work showed that 'First marriage consists of arriving at an age of marriageability (an age with a distribution that is approximately normal), followed by passage through 2 or 3 stages, the probability of passage to the next stage being approximately constant within each stage' (Coale 1977, p. 144, italics in original). Coale tentatively identifies the stages in a Western context as dating, meeting the future spouse, engagement and finally first marriage. He acknowledges a similar conceptualization of the marriage process in several papers by Henry, but apparently was not aware of these in the early stages of his work.

Rodriguez and Trussell (1980) reformulated the Coale-McNeil model to give an expression with three parameters representing the mean and standard deviation of age at marriage among those who marry, and the proportion who ever marry.

\subsection{The Hernes Model}

The development of Hernes's model (1972) seems to have taken a somewhat different course than the Coale-McNeil model. ${ }^{3}$ An initial step is the conceptualization of first marriage as a diffusion process within a cohort. The pace and extent of this diffusion are determined by several factors: an initial level of 'marriageability' characterizing the cohort; a rate at which marriageability declines with age; increasing social pressure to marry as the proportion of the cohort already married increases; and decreasing availability of potential mates as the proportion already married approaches its ultimate value.

These behavioral assumptions lead to a 'non-homogeneous diffusion' model expressed by the differential equation:

\footnotetext{
${ }^{2}$ Coale's interest in finding a behavioral rationale for the model suggests a distinction between the approach in his early work and its later treatment by the demographic community.

${ }^{3}$ I say 'seems' because a discussion of the Hernes model cannot benefit from a first-person account as contained in Coale (1977).
} 


$$
\mathrm{dP}_{\mathrm{t}} / \mathrm{dt}=\mathrm{Ab}^{\mathrm{t}}\left(1-\mathrm{P}_{\mathrm{t}}\right)\left(\mathrm{P}_{\mathrm{t}}\right)
$$

The parameter A refers to the initial marriageability; $b$ is a constant of deterioration. $P_{t}$ is the proportion married at time $t$ years from the beginning of the marriage process. The last two terms in Eq. 6.2 express the shortage of suitable mates as the proportion not yet married $\left[1-P_{t}\right]$ becomes small, and the social pressure to marry as the proportion married $\left[P_{t}\right]$ increases. The product of these two terms reaches a maximum when $P_{t}$ is 0.5 .

The parameter A is defined by Hernes as individual 'marriage potential' and is assumed to be the same for every member of the cohort - thus 'average initial marriageability.' He does not fully elaborate on this concept, which combines notions of motivation, eligibility or capacity, and the cultural value of marriage. Marriage potential is assumed to decline geometrically with age by a factor $b<1.0$. Upon integration, Eq. 6.2 yields what Hernes describes as an 'unwieldy' expression, which has no simple behavioral interpretation - the behavioral concepts are reflected in the differential equation. ${ }^{4}$

Hernes fits Eq. 6.2 to cohort data from a 1960 U.S. census publication (U.S. Bureau of the Census 1968), for two cohorts of men and woman, for whites and non-whites. He also shows that marriageability is higher but decreases more rapidly with age for more highly educated white women than for the less educated.

\subsection{Canonization Versus Relative Neglect}

In subsequent years, the Coale-McNeil model become the standard model of first marriage, while the Hernes model was largely neglected by mainstream demography. As noted already, Hernes's model was not mentioned in U.N. Manual X. Newell (1988) included it in his bibliography but did not discuss it further. Trussell and Reinis (1989) did not include it in an extensive bibliography on age at first marriage and at first birth, in a paper in which the Coale- McNeil model is featured. Keyfitz (1985), with characteristic comprehensiveness, gave Hernes several paragraphs. But overall, relative to Coale-McNeil, the Hernes model was ignored by demographers. Many otherwise well-informed demographers had never heard of it. $^{5}$

Published work on Hernes's model has been concerned largely with its formal or statistical properties, evaluating goodness of fit compared to other models, or using it to complete incomplete marriage cohort experience. Virtually no use has been made of his model to study substantive issues relating to first marriage (for

\footnotetext{
${ }^{4}$ The resulting expression is unwieldy mainly by comparison with the original differential equation, and is no more so than the Coale-McNeil equation.

${ }^{5}$ Anecdotal evidence. I became aware of the Hernes model by accident, reading the article that immediately preceded it in the journal.
} 
example, following up on his lead on educational differentials). Nor has there been much effort to develop his theoretical insights into the first marriage process, some of which now seem dated, but which certainly provided promising leads. ${ }^{6}$

How can one explain the fate of Hernes's work? The most obvious explanation overall scientific merit - would not seem to be the answer, although clearly this is a matter of subjective judgement. In terms of the usual evaluative criteria. Hernes stacks up rather well against Coale-McNeil.

Goodness of Fit Although I know of no systematic, rigorous comparison of the goodness of fit of the two models across a wide array of empirical data, published evidence and my own experience point to the conclusion that both models fit first marriage curves very well. Hastings and Robinson (1973) used Hernes to fit data on several U.S. cohorts, with relatively small errors for most of them (formal measures of goodness of fit are not reported). Diekmann (1989) concludes, based on German and U.S. data, that Hernes performs well when compared with several other models of the class evaluated (diffusion models). He comments:

...the Hernes model complies quite well with the observations while the log-logistic model yields a middling approximation to the data. However, it should be noted that the twoparameter log-logistic model is a more parsimonious parameterization than the threeparameter Hernes model. (p. 39)

He adds: 'Both models are not merely descriptions of observed data but also have considerable theoretical appeal' (p. 39). Diekmann does not consider the CoaleMcNeil model in this paper, which focuses on diffusion type models; he categorizes Coale- McNeil as a 'latent state' model.

In a direct comparison of Hernes and Coale-McNeil, Malakar (1987) concludes that Coale-McNeil provides a better fit to Indian data. But the data used are relatively poor, and in the main comparison (his Table 2) Hernes fits female (but not male) data as well as or better than Coale-McNeil. ${ }^{7}$ Measures of error are relatively small for both models.

Trussell and Reinis (1988) rely on Coale-McNeil for a comparative analysis of data from 41 WFS surveys. But they report enough problems with fitting the data (including proportions ever marrying exceeding 1.0), that one wonders why they did not consider other possible models.

Parsimony and Tractability Hernes's mathematical function is, if anything, the more elegant of the two. The differential equation is simple, flows directly from behavioral reasoning, and is transparent - that is, its behavioral interpretation is easy to see in the function itself. The Coale-McNeil convolution of normal and exponential functions probably is harder for most people to intuit or visualize. And

\footnotetext{
${ }^{6}$ There also has been a general lack of interest in the behavioral rationale for the Coale-McNeil model. Possible complementarities in the behavioral underpinnings of the two models (and consequent possibilities of synthesis) seem never to have been noted.

${ }^{7}$ I take Malakar's reported goodness of fit measures at face value, although I have been unable to reproduce his parameter values for the Hernes model using Mathcad's nonlinear fitting function.
} 
its derivation and presentation involve: a novel definition of the standard demographic notion of risk; transformations of origins, horizontal and vertical scales; and discussion of convolutions of infinite series of exponential functions. Hernes simply fits the solution to his differential equation to the data, assuming only a reasonable starting point (comparable to Coale-McNeil's $\mathrm{a}_{0}$ ). Hernes's equation has a closedform solution; the Coale-McNeil risk function does not. ${ }^{8}$ Formally, both models have three parameters, but Coale-McNeil has four additional numerical constants relating to a standard schedule of first marriage risk. In applications of CoaleMcNeil, 'Normally, the proportion single in age group 50-54 may be considered an estimate of...the proportion who will never marry' (U.N. Manual X, p. 23); the Hernes model need not assume, but generates, meaningful asymptotic values, given observations up to age 50 or so. ${ }^{9}$

Behavioral Content The Coale-McNeil model might be characterized as 'semibehavioral.' Its parameters relate primarily to formal properties of the fitted function - starting point, asymptotic value, level relative to the Swedish standard curve (in the Rodriguez-Trussell re-parameterized version (1960), the mean and standard deviation of age at marriage). They are not closely tied to or descriptive of the underlying process posited, that is, the series of waiting times. ${ }^{10}$

The notion of waiting times is itself as much formal as behavioral insofar as little is said about why there is delay in moving from one stage to another. Coale links the conceptualization to such social institutions as dating and engagement, but these ideas are not reflected directly in the model. ${ }^{11}$

The Hernes model, by contrast, deals with notions of motivation, social pressure, eligibility for marriage, and supply of mates. And, these behavioral concepts are reflected in the form of the model and in its parameters, although admittedly the parameter A confounds measures of factors the behavioral theorist would prefer to keep separate.

Logical Inference As noted above, Coale expressed concern with finding a theoretical rationale for the Coale-McNeil model, but appears to have been quickly satisfied by Feeney's suggestions and the work of Henry, both relating to a 'waiting times' conceptualization of the first marriage process. Neither in the original work

\footnotetext{
${ }^{8}$ In the sense that the integral of the risk function cannot be expressed in terms of elementary functions.

${ }^{9}$ In my experience, estimating parameters for Hernes is easier than for Coale-McNeil using the nonlinear least-squares utility in Mathcad. With Coale-McNeil, the process often breaks down due to numbers beyond the capacity of the program $\left[10^{-308}\right.$ to $\left.10^{308}\right]$. I do not know if this is a problem with other techniques or software.

${ }^{10}$ Feeney's (1972) model, based on a similar conceptualization of the process, is more graphic, in that it yields as parameters a mean age of entry into the marriage pool, a mean waiting time in the pool, and a mean age at marriage.

${ }^{11}$ There is a potential link with a large economics literature on search processes and assortative mating, but to my knowledge this link has not been developed in the demographic literature on first marriage. But see Goldstein and Kenney (2001).
} 
nor in its applications by others has there been much interest shown in the possibility of alternative conceptualizations of the marriage process.

Keyfitz (1985), in an uncharacteristic logical lapse, goes along with Coale's relaxed acceptance of the 'waiting times' theory: 'The closeness of fit of the convolution to the observed data for this and other populations confirms their behavioral model' (p. 180). Trussell and Reinis (1989) comment more accurately: 'Subsequent research has done little to either confirm or deny the behavioral interpretation of the Coale/McNeil model' (p. 132). Hernes (1972) also takes the more correct view of the situation, avoiding the logical fallacy of affirming the antecedent:

The general problem with our type of analysis is that the fit between the observed and calculated curve of first marriage is not a strong test of the model.... [I]t is hard to tell whether the resulting estimates actually reflect the causal forces involved. The model, which contains the common wisdom we began with, is clearly admissible by the data. But by the above analysis, we have not eliminated other causal processes that might generate curves of cumulative marriages with the same rough shape. (pp. 180-81)

This comment might be thought to have all the more force when the theoretical rationale for a model is provided after the fact, as in the case of Coale-McNeil.

\subsection{The Sociology of Demography}

If their relative scientific merits ${ }^{12}$ do not explain the different receptions accorded the two marriage models, what does? There are, of course, personal and institutional factors at work. Coale was located at a major demographic research institute, and had been at the center of the international demographic community as represented by International Union for the Scientific Study of Population. He continued to develop the model, and to promote its use. Hernes, by contrast, apparently wrote no more on the subject, ${ }^{13}$ and did not pursue a full-time career in social science research. At last report, he held a cabinet post in the Norwegian government.

But some part of the explanation must lie with the intellectual character of the discipline of demography. A recent quote from Newell's (1988) discussion of Coale- McNeil can serve to illustrate the point:

Coale (1971) and Coale and McNeil (1972) go to considerable lengths to try to identify a plausible behavioral explanation of the marriage process which is consistent with the double exponential form of the model. They conclude that such a form is probably a

\footnotetext{
${ }^{12}$ As assessed by this writer, of course. It is quite possible that I have overlooked some flaws or practical disadvantage in the Hernes model, or failed to see some additional virtues or advantages in Coale-McNeil.

${ }^{13}$ It is worth emphasizing the fact, however, that his article was published in what is generally considered the leading sociological journal in North America, if not the world. There is no question of inaccessibility in an obscure journal.
} 
consequence of first marriage consisting of a series of stages.... This rationalization is, however, unimportant for practical purposes. One is generally only concerned with the model's ability to fit a wide range of experience, not with its ability to reflect the underlying processes involved'. (p. 169)

Even with due regard for context (namely, a book on demographic techniques) and qualifying phrases ('for practical purposes'), it is difficult not to see in this quote a certain abdication of scientific aspirations, insofar as science is conceived of as an attempt at explanation. Process and mechanisms do not matter so much; one is content to leave the 'black box' black.

The Newell quote may be particularly blunt, but the attitude it seems to reflect is widespread in the demographic community. It would not be too-hard to document the fact that many demographers are concerned almost entirely with measurement, description, statistical modeling and the formal aspects of forecasting. There are others, many of whom would consider themselves social demographers or economic demographers rather than just demographers, who are particularly interested in explanation, and therefore in theory.

There are different ways of thinking about this situation. Perhaps it reflects a normal process of specialization and division of labor within a complex scientific field (cf. theoretical and experimental physics). Or perhaps the division has gone too far, leaving demography schizoid. There are almost 'two demographies,' one a branch of applied mathematics/statistics, focusing on measurement and formal modelling, greatly concerned with high degrees of precision, and relatively neglectful of causal explanation or theory. ${ }^{14}$ This brand of demography is often, but not always, practiced in a governmental or quasi-governmental context. The other demography is a branch of social or behavioral science, concerned with explanation of demographic phenomena (and therefore with substantive behavioral models and theory), and somewhat more tolerant of measurement error. This brand of demography is often but not always practiced in universities or free-standing research institutes.

Differing attitudes toward error in demographic measurements may be taken as hallmarks of the two demographies. The government context of much demographic work often dictates great concern with precision. The central task of a government statistical office is to collect good data, and the results are often politically sensitive. A change of 0.3 percentage points in an unemployment rate can have major political consequences. And millions of dollars were spent in legal battles over the accuracy of the 1990 U.S. census, presumably in part because many more millions of dollars were thought to be at stake. This governmental view of precision is often carried over into more academic demography, where it may have less justification except insofar as the quest for accurate measurement becomes an end in itself. In his book on demographic methods, Smith (1992) expresses reservations about a particular method because it involves data accurate 'only to two or three significant digits' (p. 84). In his Table 4.5, calculations are carried out to five

\footnotetext{
${ }^{14}$ The idea of 'two demographies' is elaborated on by McNicoll (1992) and by Olsen (1988).
} 
decimal places. Given errors in basic demographic data, perhaps only two or three significant digits may be justified. And from a scientific theoretical point of view, such precision may not be particularly important.

The problem is an old one, the classic comment that of Norbert Wiener, as quoted by Morgenstern: 'Economics is a one or two-digit science' (Morgenstern 1963). His point: there are few if any substantive propositions in economics (at all but the lowest level of generality) that would be verified or falsified depending on results in the third or fourth significant digit or decimal. ${ }^{15}$ This would be truer of behavioral demography, which has much less carefully-honed general theory.

Another view of situation described above, however, is that the theoretical aspirations of much academic demography are futile. John Q. Stewart, in a defense of some of his descriptive work on population potential, once defined science as 'the search for non-obvious regularities in the visible world.' Recent methodological writings in sociology have begun to question the feasibility of going much beyond that, suggesting that theoretical progress based on the adjudication of two or more competing theories by means of empirical research may be a chimera (Turner 1987). Turner attributes this view to Karl Pearson, for whom '...theory, in the positivist sense of an articulated logical structure, had no place' in science, and whose recommendation was '...to abandon the goal of theory in social science in favor of amassing correlational sequences...' (p. 179), what we might now call empirical generalizations. In this light, a neglect of theory may represent scientific common sense. ${ }^{16}$

In the context of the case study presented in this chapter, there are two main problems with this abstemious approach to theory. First, if 'One is generally only concerned with the model's ability to fit a wide range of experience...,' then recent developments in computerized curve-fitting may have downgraded much of demographic modeling to a clerical task. Finding a good fit to a given data set is now a trivial exercise. To give but one example, a product such as TableCurve (software from Jandel Scientific) can fit over 3,000 curves to a typical demographic data set (such as first marriage data) in a matter of seconds. Some of them might fit the data better (measured by $\mathrm{R}^{2}, \mathrm{~F}$, or mean square error) than either Coale-McNeil or Hernes. Many of them are linear forms (in the parameters), with several uninterpretable parameters. But this doesn't matter if 'One is generally only concerned with the model's ability to fit etc....'

Finding a curve that will fit 'a wide range of experience' admittedly is a more difficult task in general, but relatively easy for a phenomenon that has tended up until now to be fairly stable over time and space (for example, first marriage, which has strong biological underpinnings), and takes a characteristic pattern - it begins at

\footnotetext{
${ }^{15}$ While this view still seems valid, it may need to be qualified to take account of measurement error in complex multivariate models now commonplace in social science, as well as other forms of propagation of error generally.

${ }^{16}$ The point about 'one or two digits' might still apply, however, since it is hard to think of empirical generalizations that would stand or fall on third or higher digits.
} 
around age fifteen, is monotonic, and cannot exceed 1.0 but usually reaches 0.9 or so.

Finding a curve with behaviorally interpretable parameters is much more difficult, of course, but now one is becoming concerned with 'its ability to reflect the underlying processes involved,' in short, with theory. Finding the good-fitting curve with a theoretical rationale is the aim of mainstream social science, in contrast to the Pearsonian variant mentioned above.

Finding the model with a good theoretical rationale may also be important for purposes of measurement and prediction, even if one is only concerned with its 'ability to fit a wide range of experience.' Another reason why modeling without theory is problematic is that, if we don't know why a model fits a wide range of experience, we have many fewer clues as to whether it will continue to fit data outside that range, whether in the future or for hitherto unobserved cases. Extrapolation to other cases or beyond a range of observation remains extrapolation, whether it is based on a simple linear model, a double exponential, or a modified Gompertz. Only theory can hope to tell us whether the extrapolation is justified.

Successes to date with modeling first marriage may be partly fortuitous, and the radical changes in patterns of union formation over the last decades will require new and different models. Later home-leaving, cohabitation, and the delay and avoidance of legal marriage may lead to unprecedented low levels of proportions ever-married, and may lead to a curve of first marriage risk with opposite skewness, or even conceivably bi-modal curves with respect to age. Suitable curves will differ depending on the inclusion or exclusion of informal unions.

A graphic example of this kind of 'structural shift' is given by Fig. 6.1, which shows non-family 'headship' rates (incomplete cohort experience) for several cohorts, based on data from four Canadian censuses (1971-1986). The data are based on an unchanging census concept of 'head,' so that the changes in pattern are not artefactual. A similar structural shift can be seen in cohort data on female rates. In either case, a function that fit older cohort experience quite well would do poorly when applied to younger cohorts, and this will eventually be reflected in crosssectional data. ${ }^{17}$

The comparison with first marriage is not perfect, since accession to and relinquishment of 'household headship' are compound events, functionally related to more elementary events such as home-leaving, marriage, divorce, and widow[er] hood. But the general point is clear: mathematical models that fit well in the past may not fit well in the future. And our ability to anticipate this is based very much on a theory-based understanding of why the model fits. Well-formulated theory may be the most practical thing of all.

\footnotetext{
${ }^{17}$ It may be possible to find a functional form that would represent the varied patterns of both older and younger cohorts, but it would be considerably more complicated than functions like CoaleMcNeil or Hernes, to capture the non-monotonic character of the curves for younger cohorts.
} 


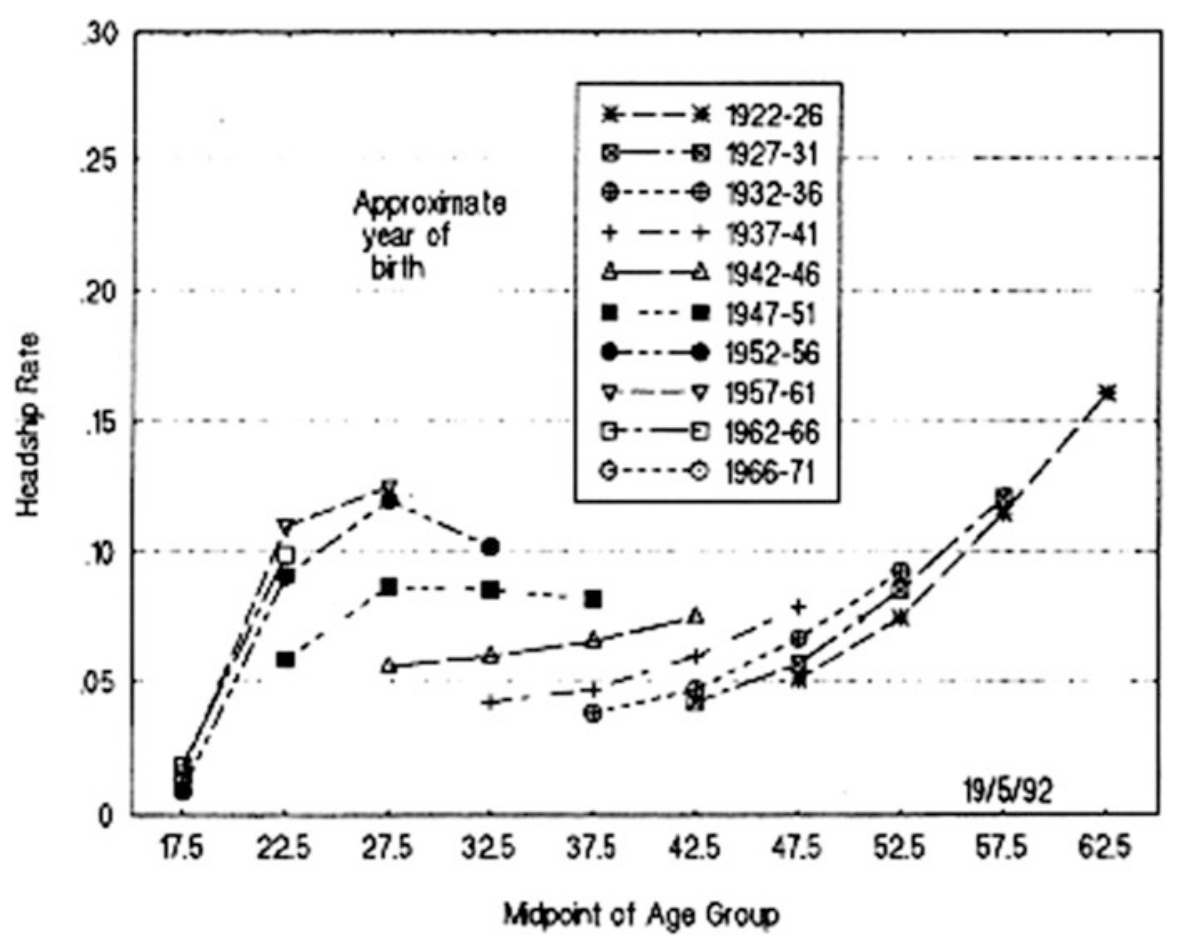

Fig. 6.1 Headship rates by age, non-family households Canadian cohorts, 1922-1926 to 1966-1971

\subsection{Afterthoughts and Updates}

The paper reprinted in this chapter is the earliest in the collection. It reflects the status of the Hernes model in demography at the time, nearly 25 years ago. It also reflects an early stage in my intellectual development, as I moved away from positivism and logical empiricism and worked to assimilate the 'semantic' or 'model-based' view of science, and to apply it to demography. Demographers are now better acquainted with the Hernes model, which is more often cited, used in research, and featured in textbooks on demographic methods.

A prime example is a 2001 paper by Goldstein and Kenney (2001) entitled 'Marriage delayed or marriage foregone? New cohort forecasts of first marriage for US women.' The authors use both the Hernes and the Coale-McNeil models to study patterns by cohort, educational level and race. The two models '...give essentially identical estimates when based on the same data' (p. 512). Unlike earlier papers, Goldstein and Kenney move beyond the issue of goodness of fit, and discuss their statistical results in light of microeconomic theories of marriage and of assortative mating. 
In his recent text, Essential Demographic Methods, Wachter (2014) mentions the Coale-McNeil model but does not discuss it in any detail. He devotes two pages to the Hernes model, noting some limitations and suggesting different approaches to estimation of the proportion eventually marrying (relying on maximum likelihood rather than least squares; p. 215). Preston et al. (Demography: Measuring and Modeling Population Processes, 2001) devote four pages to Coale-McNeil, but do not include Hernes in their bibliography. So, reference to Hernes is far from routine by demographers with an interest in modeling the marriage process.

Coale and Trussell revisited the topic in their authoritative review article on demographic models (1996). In the section on nuptiality, they devote almost as much space to the Hernes model as to Coale-McNeill, noting that it provides very close fits to observed marriages schedules by race and sex in the United States (p. 477). They state three differences between the two: (1) Hernes is based on 'explicit sociological assumptions'; (2) '... Hernes's model, unlike that of Coale and McNeill, allows a closed-form expression for the proportions ever married by age'; (3) Coale and McNeil's model, unlike Hernes's has been extensively used by demographers.' They comment further: 'Hernes's model is both simple and intuitively appealing; it has deserved and still deserves more attention by demographers (p. 477). A closing comment on the role of theory in the kinds of models reviewed (presumably including marriage models) appears to represent a departure from Coale's earlier view as quoted above, where he '...expressed dissatisfaction with the double exponential risk function on the grounds that it did not provide any evident basis for an intuitive understanding of first marriages. In other words, it did not suggest a theory or model of nuptiality' (Coale 1977, p. 140, emphasis added). In an overall characterization of the models, Coale and Trussell note: 'The models are descriptive and were never intended to be anything else. No deep theory, or even shallow theory, underlies the search for empirical regularities. In contrast, the discovery of empirical regularities can stimulate the search for underlying causes' (1996, p. 483). But they comment further that '...finding a mathematical expression to represent a demographic process is not an end in itself. The models are valuable because they can be used to make broad inferences about behavior or, more commonly, to build a technique for estimating basic demographic indices for populations with limited or defective data' (p. 483).

Read together the above quotes suggest ambivalence about the role of theory in demographic research. One might try to develop theory eventually, but the main tasks for the demographer are empirical research, modeling, measurement and estimation. There is but a qualified interest in theory.

Part of the problem, perhaps, is that many of us have had an outdated and inappropriate view of what theory is and how it works. The 'search for empirical regularities' is key; they are the building blocks of theory, not just a stimulus for theoretical thinking. And by the doctrine of falsification, we search for one best theory, the scientific equivalent of monotheism. My own writing in this sometimes reflects these older views of theory. The comparison of the two models comes close to suggesting that we adopt Hernes rather than Coale-McNeil. I now firmly believe in the 'toolbox' approach to theory and models, and the centrality of purpose in 
evaluating a given model. The two models are qualitatively different, one a diffusion model, the other a 'latent states' or waiting-time model. Their behavioral content is different, giving different perspectives on the first-marriage process. For some purposes, the Coale-McNeill model may be better than Hernes in the attempt to gain insight into certain aspects of marriage behavior and its causes. But still, if one is not concerned with social and behavioral explanation, if one is only interested in fitting empirical data on first marriage, then Hernes would seem the better choice - it's simpler, more intuitive, and fits most empirical data equally well.

\section{References}

Coale, A. J. (1971). Age patterns of marriage. Population Studies, 25, 193-214.

Coale, A. J. (1977). The development of new models of nuptiality and fertility. Population [numero special], 32, 131-152.

Coale, A. J., \& McNeil, D. (1972). The distribution by age of the frequency of first marriage in a female cohort. Journal of the American Statistical Association, 67, 743-749.

Coale, A. J., \& Trussell, J. (1996). The development and use of demographic models. Population Studies, 50, 469-484.

Diekmann, A. (1989). Diffusion and survival models for the process of entry into marriage. Journal of Mathematical Sociology, 14, 31-44.

Feeney, G. (1972). A model for the age distribution of first marriage (Working Paper No. 23, 31pp). Honolulu: East-West Population Institute.

Goldstein, J., \& Kenney, C. T. (2001). Marriage delayed or marriage foregone? New forecasts for US women. American Sociological Review, 66, 506-519.

Griswold, W. (1987). A methodological framework for the sociology of culture. Sociological Methodology, 1-35.

Hastings, D. W., \& Robinson, J. G. (1973). A re-examination of Hernes's model on the process of entry into first marriage for United States women, cohorts 1891-1945. American Sociological Review, 38, 138-142.

Hernes, G. (1972). The process of entry into first marriage. American Sociological Review, 37, $173-182$.

Keyfitz, N. (1985). Applied mathematical demography (2nd ed.). New York: Springer-Verlag.

Malakar, C. R. (1987). On recent developments of marriage models and their application to Indian nuptiality. Genus, 43, 93-101.

McNicoll, G. (1992). The agenda of population studies: A commentary and complaint. Population and Development Review, 18, 399-420.

Morgenstern, O. (1963). On the accuracy of economic observations (2nd ed.). Princeton: Princeton University Press.

Newell, C. (1988). Methods and models in demography. London: Belhaven.

Olsen, R. J. (1988). Review of 'Models of marital status and childbearing,' by M. Montgomery \& J. Trussell. In O. Ashenfelter \& R. Layard (Eds.), Handbook of labor economics. The Journal of Human Resources 23, 577-583.

Preston, S. H., Heuveline, P., \& Guillot, M. (2001). Demography: Measuring and modeling population processes. Oxford: Blackwell Publishers.

Rodriguez, G., \& Trussell, J. (1980). Maximum likelihood estimation of Coale's model nuptiality schedule from survey data (WFS Technical Bulletin No. 7). London: World Fertility Survey.

Smith, D. P. (1992). Formal demography. New York: Plenum Press.

Trussell, J., \& Reinis, K. I. (1989). Age at first marriage and age at first birth. Population Bulletin of the United Nations No. 26 (pp. 126-194). New York: United Nations. 
Turner, S. P. (1987). Underdetermination and the promise of statistical sociology. Sociological Theory, 5, 172-184.

United Nations, Department of International Economic and Social Affairs. (1983). Manual X: Indirect techniques for demographic Estimation (Population Studies \#81). New York: United Nations.

Wachter, K. W. (2014). Essential demographic methods. Harvard University Press.

Open Access This chapter is licensed under the terms of the Creative Commons Attribution 4.0 International License (http://creativecommons.org/licenses/by/4.0/), which permits use, sharing, adaptation, distribution and reproduction in any medium or format, as long as you give appropriate credit to the original author(s) and the source, provide a link to the Creative Commons license and indicate if changes were made.

The images or other third party material in this chapter are included in the chapter's Creative Commons license, unless indicated otherwise in a credit line to the material. If material is not included in the chapter's Creative Commons license and your intended use is not permitted by statutory regulation or exceeds the permitted use, you will need to obtain permission directly from the copyright holder.

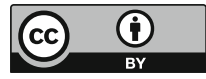

